\title{
Historical Perspectives of The American Association for Thoracic Surgery: Fredrick G. Kergin, MD (1907-1974)
}

\author{
Myunghyun Lee, MD, and Vivek Rao, MD, PhD
}

\author{
From the Division of Cardiovascular Surgery, Peter Munk Cardiac Centre, Toronto General Hospital, University \\ of Toronto, Toronto, Ontario, Canada. \\ Disclosures: Authors have nothing to disclose with regard to commercial support. \\ Received for publication Nov 7, 2015; accepted for publication Nov 10, 2015; available ahead of print Jan 5, 2016. \\ Address for reprints: Vivek Rao, MD, PhD, Toronto General Hospital, 4N-457, 200 Elizabeth St, Toronto, \\ Ontario, Canada M5G 2C4 (E-mail: vivek.rao@uhn.on.ca). \\ J Thorac Cardiovasc Surg 2016;151:903-5 \\ $0022-5223 / \$ 36.00$ \\ Copyright (C) 2016 by The American Association for Thoracic Surgery \\ http://dx.doi.org/10.1016/j.jtcvs.2015.11.013
}

Fredrick Gordon Kergin, MD, was born in 1907, the youngest son of a doctor's family in British Columbia, Canada. He attended college in Toronto at age 16 years, and after completing his undergraduate degree, Dr Kergin pursued studies in medicine at the University of Toronto, from which he graduated as a silver medalist in 1930. He was awarded a Rhodes scholarship in 1931, and spent 2 years studying at Oxford University, fulfilling the requirements of the Royal College of Surgeons of England, as well as completing a Master's degree in physiology and anatomy. As part of the Gallie Course in Surgery, Dr Kergin completed his postgraduate surgical training in Toronto and London. He was awarded fellowships in surgery from the Royal Colleges of England and Canada in 1935 and 1939, respectively. In 1937, Dr Kergin began his surgical practice at Toronto General Hospital. Later, he returned to London to deliver the Hunterian Lecture, to the Royal College of Surgeons of England on July 28, 1955. The title of his lecture, later published in the college's journal"The Treatment of Chronic Pleural Empyema"-is a subject that consumed most of his clinical and academic practice (Figures 1 and 2). 1,2

At the time Dr Kergin began his surgical career at Toronto General Hospital, he had the privilege to work in close collaboration with Robert M. Janes, MD (32nd president of The American Association for Thoracic Surgery; 1952-1953), with whom he formed a great friendship. Dr Janes, a senior consultant at the hospital, became Dr Kergin's colleague and mentor. From that point, Dr Kergin's career closely followed that of Dr Janes, as exemplified by his appointments as chief of a surgical division at Toronto General Hospital, and subsequently surgeon-in-chief at Toronto General Hospital, as well as professor and chairman of the Department of Surgery at the University of Toronto (1957-1966). Like Dr Janes, he became the chairman of the editorial board of the Canadian Journal of Surgery (1965-1972); last, but not least, he was the 47th president of The American Association for Thoracic Surgery (1966-1967).

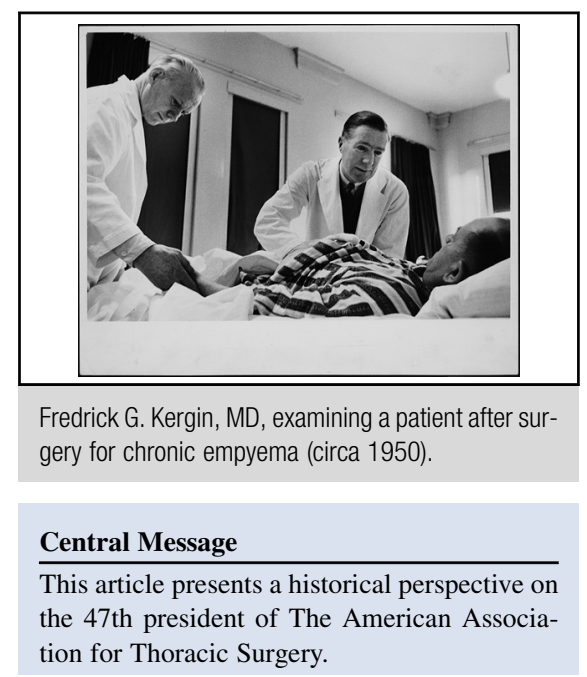

Although both Dr Kergin and Dr Janes trained as general surgeons with an interest in thoracic surgery, they initially had differing views regarding the creation of thoracic surgery as a separate division. Although Dr Janes was a firm supporter of having thoracic surgery as a unique discipline, distinct from general surgery, Dr Kergin was at first opposed to the creation of this division. However, after asking Dr Norman C. Delarue to undertake "a thorough study of the changing picture across Canada pertaining only to the thoracic surgical aspects and not include reference to the cardiovascular scene," ${ }^{1}$ and with increasing encouragement from Dr Janes, Dr Kergin decided to support the establishment of the Division of Thoracic Surgery at Toronto General Hospital in 1966, before the end of his tenure as chair of surgery. The significance of this event was monumental, as the thoracic surgical division at Toronto General Hospital was the first of its kind in Canada. After its creation, the Division of Thoracic Surgery in Toronto played a key role in the establishment of training requirements for thoracic surgeons and the creation of the Royal College certification criteria for other hospitals throughout the nation.

Dr Kergin's involvement with thoracic surgery dates back to his participation in the Royal Canadian Army Medical Corps during the Second World War. He had worked as a senior surgeon at the No. 15 Canadian General Hospital in North Africa, and received promotion to the rank of lieutenant colonel before the end of the war. According to W.A. 


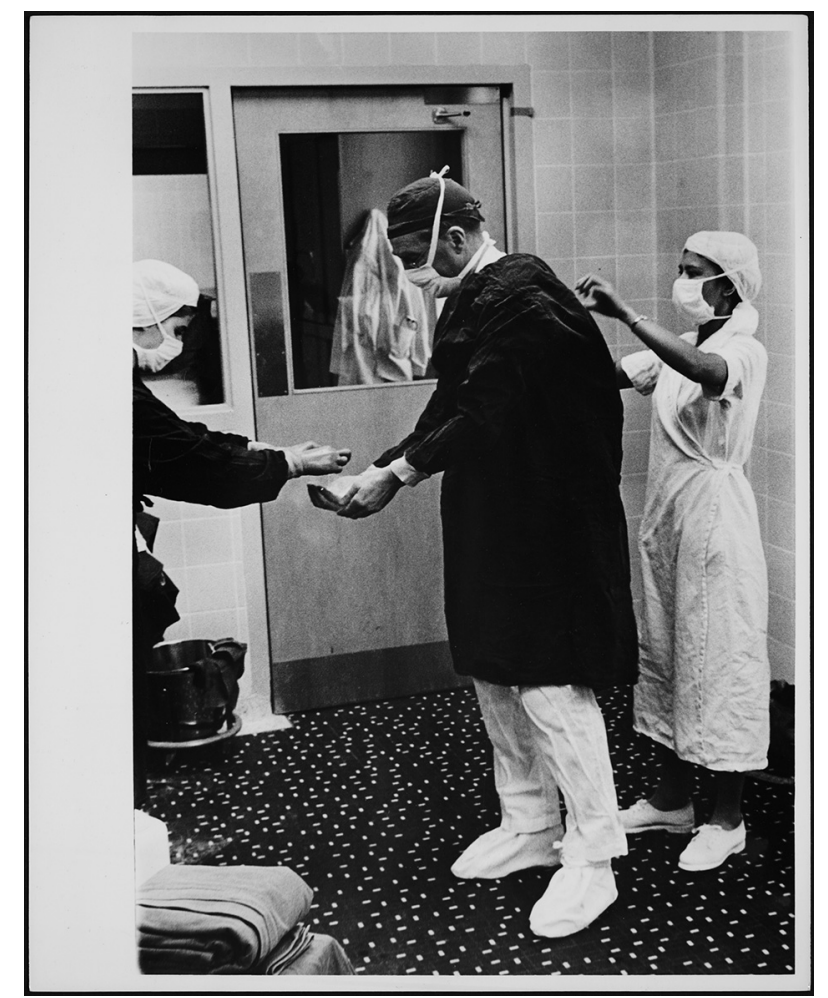

FIGURE 1. Kergin (circa 1960) having his hands washed in preparation for surgery at the Toronto General Hospital.

Oille, $\mathrm{MD}^{3}$ : “...apart from the casualties of the Dieppe Raid, it was not until the Canadian forces entered the Mediterranean theatre that a large group of chest wounds was encountered." Indeed, the early experiences in the Mediterranean campaign were carefully documented and studied by Oille and Kergin, and they were able to lay the foundation of treatment policies for the later portions of the war. As an

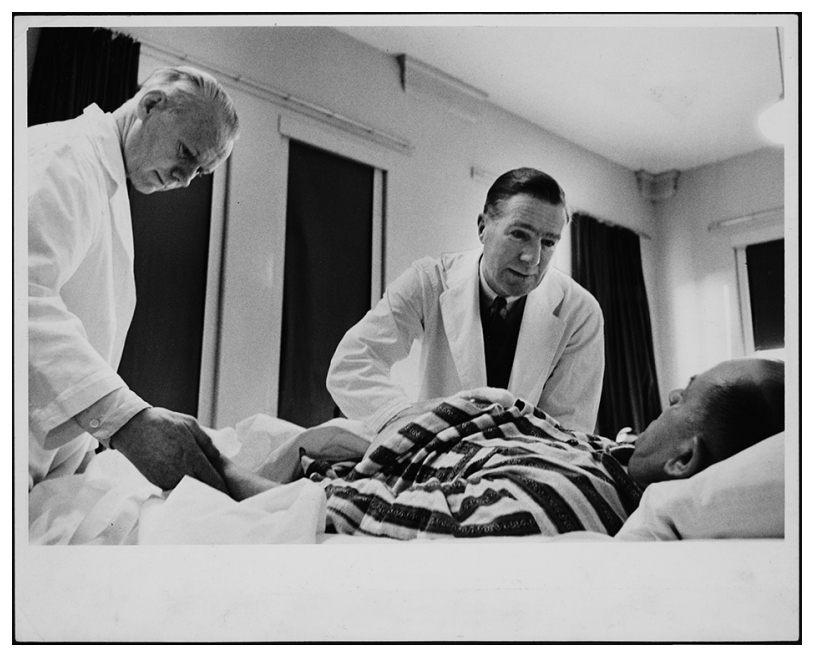

FIGURE 2. Fredrick G. Kergin, MD, examining a patient after surgery for chronic empyema (circa 1950). example, prior to the war, traditional teachings maintained that "aspiration of blood encouraged further bleeding, that repeated aspiration might introduce infection, and that intrapleural blood could be absorbed in the absence of tissue destruction leading to coagulation cascade on the pleural surface." 1

According to Dr Delarue, ${ }^{1}$ perhaps Dr Kergin's greatest achievement was challenging the traditional views, as a true pioneer of his time. This effort was later highlighted in a presentation by $\mathrm{Dr}$ Oille, ${ }^{3}$ in which Dr Kergin emphasized, contrary to prevailing views at the time, that daily aspiration of pleural blood encouraged control of bleeding by the tamponading effect of lung expansion, and that the early obliteration of pleural space provided excellent prevention of empyema, and of fibrothorax. After the success of Dr Kergin's discoveries, based on his meticulous charting and observations during the earlier phase of the war, later, official policy was to open the chest deliberately and decorticate the lung for the surgical treatment of infected hemothoraces. ${ }^{2,4-6}$

After his retirement from active clinical practice, Dr Kergin maintained a key role as an associate dean at the university. During this time, he was responsible for transforming Sunnybrook Hospital from a veterans' hospital to a teaching hospital affiliated with the University of Toronto. Dr Kergin's wartime experience additionally had a significant influence during the transformation of Sunnybrook Hospital into an academic institution, while simultaneously recognizing its significance to war veterans. Regarding Dr Kergin at this phase of his career, Cosbie recalled $^{1}$ that:

Dr Kergin's wartime experience had influenced his reaction to the semi-autonomous nature of the special divisions of the Departments of Surgery, and he appreciated the great advantage of developing a closer relationship with similar services in the other teaching hospitals. There was a strong movement towards this latter ideal, as a considerable number of the staff at the General hospital also held appointments at Sunnybrook Hospital, where the camaraderie of wartime service was breaking down outworn prejudices against close interdepartmental relations in finding new answers to old problems.

Dr Kergin's efforts made it possible to unite the various departments within the division of surgery, with a focus on a common goal: to ensure the highest standard of patient care. In the words of the Kergin Surgical Society, formed by a group of young surgeons who were fortunate to have worked with Dr Kergin as his residents, he was seen as a mentor who "derived greatest pleasure from his role as a teacher, and was both selfless and tireless in the effort to assist students of surgery in understanding their specialty 
and in the development of their careers." ${ }^{1}$ Peerless in his devotion to supporting his residents and helping them achieve the highest surgical standards, Dr Kergin was truly a "superb and uncanny" clinician who never lost his enthusiasm for medical advancements.

Judging from this fond description, the fact that his residents truly endeared him as a friend, mentor, and great role model for all those following in his footsteps is not surprising. Although Dr Janes may be known as one of the first chest surgeons in Toronto, Dr Kergin was the one who officially recognized the subspecialty, and ultimately laid the foundation for a rich tradition of training academic thoracic surgeons, many of whom have gone on to leadership positions throughout North America. This contribution is recognized by the annual Kergin Lecture, first sponsored in 1978 by the Department of Surgery at the University of Toronto, after Dr Kergin's death in 1974.

\section{References}

1. Delarue NC. Thoracic Surgery in Canada-A Story of People, Places, and Events-The Evolution of a Surgical Specialty. Toronto: B.C. Decker, Inc; 1989.

2. Kergin FG. The treatment of chronic pleural empyema. Ann R Coll Surg Engl. 1955; 17:271-90.

3. Feasby WR, ed. Official History of the Canadian Medical Services 1939-1945. Ottawa: Authority of the Minister of National Defence; 1953.

4. Kergin FG. An operation for chronic pleural empyema. J Thorac Surg. 1953;26:430-4.

5. Kergin FG. The pathology and treatment of war wounds. Can Med Assoc J. 1945; 52:543-9.

6. Kergin FG. The application of the principles of military surgery to civilian practice. Univ Toronto Med J. 1946;23:186-8. 